\title{
MORFOLOGIA DA FLOR, FRUTO, SEMENTE, PLÂNTULA E MUDA DE Cabralea canjerana (Vell.) Mart.
}

Palavras chave:

Meliaceae

canjerana

processo germinativo

Histórico:

Recebido 07/03/2012

Aceito 07/04/2015

Keyworks:

Meliaceae

canjerana

germination process

Correspondence: marcielefelippi@utfpr.edu.br
RESUMO: Foram realizadas coletas de material botânico de 20 árvores matrizes de Cabralea canjerana (Vell.) Mart., no Município de Frederico Westphalen, RS. Os aspectos morfológicos de flores, frutos, sementes, germinação, plântula e muda foram obtidos por meio de observações, medições e ilustrações. A inflorescência é paniculada, racimosa, com flores pequenas, hermafroditas. $O$ fruto simples é uma cápsula septífraga, semicarnosa, de coloração vermelho-escura, tardiamente deiscente. As sementes, de I a 10 por fruto, sendo I a 2 unidas em cada lóculo, de formato elipsóide a subesférico, com tegumento fino, coloração castanha, são envolvidas inteiramente por arilo de coloração laranja-avermelhada. Internamente, as sementes são exalbunimosas, com embrião axial, invaginado, cotilédones de forma ovóide, carnosos, eixo hipocótilo-radicular de formato cônico, curto e espesso. A germinação é semi-hipógea e a plântula fanerocotiledonar. $O$ comprimento de frutos e sementes foi variável, sendo que os frutos variaram de 2 a 2,9 $\mathrm{cm}$ de comprimento, 2,2 a $3,1 \mathrm{~cm}$ de largura e 2,2 a $3 \mathrm{~cm}$ de espessura, enquanto que as sementes variaram de 0,7 a $0,8 \mathrm{~cm}, 0,63$ a $0,75 \mathrm{~cm}$ e 0,5 a $0,6 \mathrm{~cm}$, respectivamente. Após quatro meses da germinação, a muda, já formada, possui altura média de $18 \mathrm{~cm}$ e diâmetro do colo em torno de $3 \mathrm{~mm}$. Através das características morfológicas, é possível, juntamente com as ilustrações, a identificação da espécie em seu ambiente natural, assim como o auxílio em análises laboratoriais.

\section{MORPHOLOGY OF FLOWER, FRUIT, SEED, PLANTLET, SEEDLINGS OF Cabralea canjerana (Vell.) Mart.}

ABSTRACT: Collections of botanical material from 20 trees of Cabralea canjerana (.Vell) Mart were conducted in the city of Frederico Westphalen, RS. The morphological features of flowers, fruits, seeds, germination, plantlet and seedling were obtained through observations, measurements and illustrations. The inflorescence is paniculate, racemosa with small hermaphrodite flowers. The simple fruit is a septifragal capsule, semifleshy of dark red coloration, late dehiscence. Seeds range from I to 10 per fruit, being $I$ or 2 together in each subesferical ellipsoid shape locule with thin tegument of brownish coloration, entirely surrounded by aryl orange-red coloration. Internally, the seeds are unalbuminous with axial embryo, invaginate, cotyledons of ovoid shape, fleshy, the hypocotyl-root axis is conic, short and thick. Germination is semi-hypogeal and the seedling phanerocotylar. The length of fruits and seeds was variable, and the fruits ranging from 2 to $2,9 \mathrm{~cm}$ long, 2,2 to $3,1 \mathrm{~cm}$ wide and 2,2 to $3 \mathrm{~cm}$ thick, while the seeds ranged from 0,7 to $0,8 \mathrm{~cm}$, from 0,63 to $0,75 \mathrm{~cm}$ and 0,5 to $0,6 \mathrm{~cm}$, respectively. Four months after germination, seedlings, already formed, had an mean of $18 \mathrm{~cm}$ height and stem diameter of about $3 \mathrm{~mm}$. Through morphological characteristics, it is possible, along with the illustrations, the identification of the species in its natural environment, as well as assistance in laboratory analyzis. 


\section{INTRODUÇÃO}

A determinação dos aspectos morfológicos possui importância fundamental na compreensão do ciclo de vida e crescimento de espécies florestais (MOURÃO et al., 2002), podendo auxiliar na interpretação de testes de germinação, armazenamento e viabilidade de sementes, produção de mudas (BELTRATI, 1994), além da identificação a campo, bem como o reconhecimento de estágios iniciais de crescimento em trabalhos de regeneração natural (BOTELHO et al., 2000), contribuindo para o estabelecimento de estratégias de restauração e conservação genética (SANTANA et al., 2009).

A necessidade de se dispor de um maior número de dados e informações morfológicas permitem caracterizar as espécies e diferenciá-las, auxiliando em trabalhos de inventários e de manejo florestal (PAOLI; BIANCONI, 2008).

Apesar de estudos morfológicos estarem cada vez mais frequentes, ainda estão restritos a poucas espécies, como os mencionados por Cunha e Ferreira (2003), Araújo et al. (2004), Oliveira et al. (2006), Paoli e Bianconi (2008), Felippi et al. (20I2), Felippi et al. (20।3) e Bao et al. (20|4).

Cabralea canjerana (Vell.) Mart., conhecida como canjerana, é considerada uma das espécies madeireiras mais valiosas do Sul do Brasil (REITZ et al., 1988), podendo ser empregada na construção civil, recuperação de áreas degradadas, reflorestamento, medicina popular e indústria de tinturaria e perfume (CARVALHO, 2003), no entanto, várias são as lacunas a serem preenchidas ou complementadas a seu respeito, destacando-se a caracterização morfológica.

Portanto, este trabalho objetivou descrever e ilustrar caracteres morfológicos da flor, fruto, semente, germinação, plântula e muda de Cabralea canjerana.

\section{MATERIAL E MÉTODOS}

O estudo foi realizado de março de 2007 a março de 2010, no Município de Frederico Westphalen

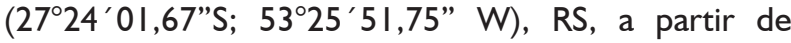
indivíduos localizados em duas áreas com distância de 3 km entre si, com 60,34 e 50 ha, respectivamente. Ambas as áreas são de Floresta Estacional Decidual, localizadas a $566 \mathrm{~m}$ de altitude. A classificação climática, segundo Köppen, é do tipo $\mathrm{Cfa}$, caracterizado por precipitação média anual elevada, I.800 a $2.100 \mathrm{~mm}$, e temperatura média anual em torno de $18^{\circ} \mathrm{C}$ (RIO GRANDE DO SUL, 200I).

$\mathrm{Na}$ área de estudo foram observadas 20 árvores matrizes, considerando para seleção os indivíduos adultos, com copa bem distribuída e fuste reto, distantes pelo menos 100 m entre si, conforme sugerido por PinãRodrigues et al. (2007). A distância mínima entre matrizes foi mantida, levando em consideração, o sistema sexual das plantas (PENNIGTON, I98I).

As árvores foram monitoradas mensalmente com o auxílio de binóculo, sendo observada a presença de floração e frutificação. Durante as observações fenológicas, foram coletados, aleatoriamente, na copa de cada árvore matriz, 50 flores e 10 frutos maduros e inteiros de sete indivíduos com frutificação sincronizada, em novembro de 2007 e armazenados em álcool (70\%) para posterior análise e ilustração morfológica no laboratório de sementes do Departamento de Ciências Florestais na UFSM.

Foram considerados frutos maduros aqueles de coloração avermelhada. Os frutos de cada matriz foram armazenados em sacos plásticos até a abertura completa dos mesmos e liberação das sementes (INOUE, 1978); para posterior análise.

A caracterização morfológica foi realizada por meio de análise externa e interna de flores, frutos e sementes e externa da germinação, plântula e muda. Foram utilizados lupa de mesa do tipo SZ40 Olympus e paquímetro mecânico (I/50 mm).

$\mathrm{Na}$ descrição das flores de cada matriz, analisou-se o tipo de inflorescência; número e disposição de cada um dos verticilos florais; posição do ovário; sexo; número, coloração e textura de pétalas e sépalas. Nos frutos, observou-se a textura, a consistência, a pilosidade, a forma e o número de sementes por fruto. Já nas sementes, observaram-se a cor, a consistência, a forma, a superfície, o tamanho, a micrópila, a rafe e o hilo. No embrião foi observada sua posição, forma e tamanho, assim como, textura e forma dos cotilédones.

Tanto para frutos quanto sementes, utilizandose 200 exemplares de cada, foram registrados os valores correspondentes a mínima, máxima e a média referente ao comprimento, a largura e a espessura (OLIVEIRA et al., 2006). 
Para o acompanhamento e ilustrações da germinação e do desenvolvimento da plântula, as sementes foram colocadas para germinar em substrato papel germitest, em germinador do tipo Mangelsdorf, sob temperatura de $25^{\circ}$ $C$, na presença de luz branca, sendo utilizadas duas repetições de 20 sementes cada. Foi realizada semeadura direta em 50 sacos de polietileno, para análise, descrição e ilustração dos indivíduos que atingiram $3 \mathrm{~mm}$ de diâmetro do colo e $20 \mathrm{~cm}$ de altura, considerados muda conforme Gonçalvez e Benedetii (200I). Os elementos vegetativos descritos e ilustrados foram raiz, colo, hipocótilo, epicótilo, cotilédones, eófilo e metáfilo.

A metodologia e a terminologia para descrição morfológica basearam-se nos trabalhos de Barroso et al. (1999), Souza (2003) e Gonçalves e Lorenzi (20 I I).

\section{RESULTADOS E DISCUSSÃO}

A folha adulta (metáfilo) é oposta, composta, paripenada com folíolos opostos (Figura I - A). A inflorescência é constituída por grupos de pequenas flores branco-esverdeadas com prefloração imbricada. É possível encontrar frutos em desenvolvimento e flores abertas no ápice. A inflorescência é paniculada, racimosa com eixos longos ou curtos.

As flores possuem brácteas de formato deltóide e uma ou mais bractéolas. São pediceladas, cíclicas, diclamídeas, heteroclamídeas, hermafroditas, diplostêmones, com nectário de coloração amarela em forma de anel, intumescido, pubescente, circundando a base do ovário e estilete (Figura I - E). O cálice é de

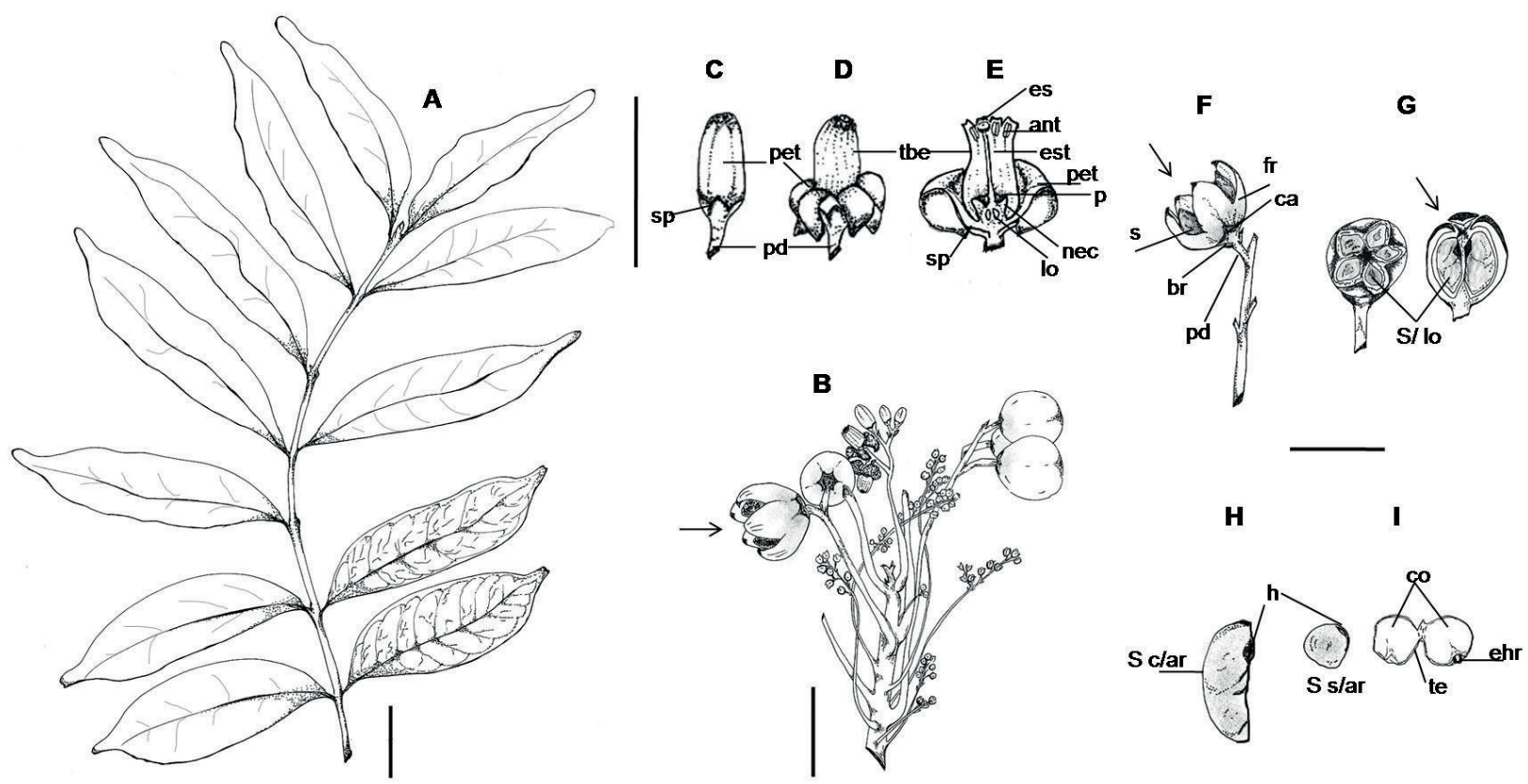

Figura 1 Cabralea canjerana. A - Folha composta; B - Ramo com botões, flores e frutos; C - Botão; D - Flor inteira; E - Flor corte/ transversal; F - Fruto aberto; G - Fruto/ corte transversal e longitudinal; H - Sementes com e sem arilo; I Semente corte transversal (ant - antera; br - bractéolas; ca - cálice; co - cotilédone; ehr - eixo hipocótilo radicular; es - estigma; est - estilete; fr - fruto; $\mathrm{h}$ - hilo; lo - lóculo; nec - nectário; $\mathrm{p}$ - pelos absorventes; pd - pedúnculo; pet - pétala; s - semente; S/lo - semente/ lóculo; S c/ar - semente com arilo; S s/ar - semente sem arilo; sp - sépalas; tbe - tubo estaminal; te - tegumento). Barra: $3 \mathrm{~cm}(\mathrm{~A}, \mathrm{~B}) ; 2 \mathrm{~cm}(\mathrm{C} \mathrm{a} \mathrm{G})$ e $0,8 \mathrm{~cm}(\mathrm{H}$; I).

Figure 1 Cabralea canjerana. A - Compound leaf, B - branch with buds, flowers and fruits; C - Button; D - Whole flower; E Flower cut / cross, F - Fruit open; G - Fruit / cross-sectional and longitudinal; H - Seeds with and without arilo; I - Seed cross section (ant - anther; br - bracteoles, ca - cup; co - cotyledon; ehr - hypocotyl root; es - stigma; est - stylus; fr - fruits; h - hilus; it - locule , nec - nectary; p - absorbing hair; pd - stalk; pet - petal; s - seed; S / lo - seed / locule; S c/ ar - seed with arilo; S s / ar - seed without arilo; sp - sepals; te - staminal tube; te - tegument). Bar: $3 \mathrm{~cm}(\mathrm{~A}, \mathrm{~B}), 2 \mathrm{~cm}$ (C to $\mathrm{G})$ and $0.8 \mathrm{~cm}(\mathrm{H}, \mathrm{I})$. 
coloração verde, dialissépalo, pentâmero, actinomorfo, com pétalas de coloração branca, dialipétala, pentâmera, actinomorfa (Figura I - C a E), enrolando-se para fora quando a flor se abre (Figura I - D e E).

A corola possui de 0,3 a $0,5 \mathrm{~cm}$ de altura e 0,3 a $0,4 \mathrm{~cm}$ de largura. Os estames, em número de dez, são fusionados entre si constituindo o tubo estaminal, com 0,7 a I cm de altura, sendo, este, pubescente na base, envolvendo o nectário e o gineceu, e deixando exposto apenas o estigma (Figura I - E), com anteras de coloração amarelo-ouro, rimosas.

A presença de estames fusionados entre si, constituindo o tubo estaminal está de acordo com a descrição de Styles (1972), o qual cita, como uma das características da subfamília Melioideae, resultado da fusão total ou parcial dos filetes.

gineceu é unicarpelar, terminal, com ovário piloso, adnato em sua base ao tubo estaminal, nectário e pétalas, caracterizando-o como semi-ínfero, diferindo da descrição realizada por Barroso et al. (1999), os quais citam para a subfamília Melioideae a presença de ovário súpero.

Já a flor é perígina, com placentação axial (Figura I - A; B), 5 lóculos, tendo I a 2 óvulos cada lóculo, superpostos, com estilete piloso somente na base, estigma indiviso e capitado (Figura I - E). O tipo de placentação, pouco citado em trabalhos, confere com o descrito por Moscheta (1995), sendo semelhante à maioria das espécies da família Meliaceae, conforme descreveram Pennington e Sytes (1975).

Em relação à sexualidade da planta, Moscheta et al. (2002) citam a presença de flores diclinas femininas com anteras estéreis e masculinas com a presença de ovário menos desenvolvido, óvulos estéreis, porém, com anteras formando abundante quantidade de pólen. Portanto, mesmo as plantas sendo hermafroditas, como descrito nesse estudo, possuem comportamento dióico.

Tais constatações também foram relatadas por Pennington e Styles (1975), Pennington (I98I) e Moscheta (1995), sendo que Styles (1972), estudando a biologia floral de várias espécies de Meliaceae, chamou a atenção para a dificuldade do reconhecimento correto das flores, uma vez que o ovário e as anteras, aparentemente desenvolvidos, não são funcionais na mesma flor.

O fruto é simples, semicarnoso, tardiamente deiscente, cápsula globosa, abertura septífraga, polispérmico, monocárpico (Figura I - G a I), com ápice arredondado e base estreitada de cima para baixo, internamente provido de 4 a 5 valvas e grossa coluna central. $\bigcirc$ epicarpo é glabro, inicialmente vermelhoclaro e salpicado de verde, passando a vermelhoescuro na maturação. $O$ cálice permanece presente até a maturação, considerado séssil, com a presença de bractéolas (Figura I - F).

Em cada fruto, há presença de I a 10 sementes, reunidas de uma a duas unidades em cada lóculo, envolvidas inteiramente pelo arilo carnoso e suculento (Figura I - H), de coloração laranja-avermelhada. Externamente, as sementes possuem formato elipsóide a subesférico (Figura I - H). O tegumento é fino, liso, de coloração castanho-clara brilhante, enquanto que o hilo é alongado, e a micrópila identificada como uma elevação do tegumento. Internamente, as sementes são classificadas como exalbuminosas, com embrião axial, invaginado, cotilédones de forma ovóide, carnosos, de coloração verde-clara e textura lisa. 0 eixo hipocótilo-radicular é de formato cônico, curto e espesso (Figura I - I).

O fruto das Meliaceae pode ser do tipo cápsula loculicida, cápsula septífraga, baga ou drupa (Pennington; Styles, 1975). O fruto de Cabralea canjerana é uma cápsula septífraga, mas, diferentemente de Cedrela fissilis (Pennington, 198I), a coluna central não alcança toda a extensão do fruto. A caracterização do fruto está de acordo com a descrição de Souza (2003), no entanto, Moscheta (1995), Carvalho (2003) e Gonçalves e Lorenzi (20I I) utilizaram outras classificações, como frutos do tipo cápsula elipsóide, sub-esférica e loculicida.

A presença de frutos carnosos, deiscentes, de acordo com Barroso et al. (1999), é frequente ao gênero Cabralea, sendo, muitas vezes, confundido com uma baga.

O cálice, considerado séssil, com a presença de bractéolas (Figura I - F), também foi descrito por Moscheta (1995). Já a presença de arilo, está de acordo com Pizo e Oliveira (1998), Backes e Irgang (2002) e Souza (2003).

De acordo com Corner (1976), qualquer excrescência carnosa que se forma na superfície do óvulo ou da semente, localizados em pontos diversos do tegumento externo e variável em seu desenvolvimento conceitua-se como arilo. Corner (1976) considera as sementes ariladas como as mais primitivas dentro da 
Meliaceae e aquelas com sarcotesta, como derivadas. No entanto, Van Der Pjil ( 1982), considera o arilo como estrutura derivada e a sarcotesta como primitiva.

A presença de arilo nas sementes as torna atrativas para pássaros e mamíferos, estando associada à dispersão (PIZO, 1997). De acordo com Barroso et al. (1999), a presença de arilóide ou de sarcotesta é uma característica do gênero Cabralea.

O formato das sementes também foi considerado diferente, quando comparado a descrições de outros autores. Carvalho (2003) cita-as como ovóides. Moscheta (1995) salienta que, quando únicas no lóculo, são elipsóides a subesféricas e, quando duplas, pode haver faces planas na região de contato entre ambas.

As dimensões de frutos e sementes tiveram ampla variação, sendo que os frutos variaram de 2 a 2,9 $\mathrm{cm}$ de comprimento, 2,2 a $3,1 \mathrm{~cm}$ de largura e 2,2 a $3 \mathrm{~cm}$ de espessura, enquanto que as sementes variaram de 0,7 a 0,8 cm, 0,63 a 0,75 cm e 0,5 a 0,6 cm, respectivamente.

A variação no tamanho de frutos e sementes, provavelmente, deve-se à variabilidade genética das diferentes árvores matrizes e à influência ambiental durante o desenvolvimento, concordando com Santos et al. (2009). Assim, a biometria pode variar entre plantas da mesma espécie, de ano para ano, como também na mesma planta, como já relatado por PiñaRodrigues e Aguiar (1993). De qualquer forma, os dados morfométricos têm indiscutível valor ecológico, auxiliando na determinação da variabilidade da espécie, bem como no estudo da dispersão e agentes dispersores.

A germinação de canjerana foi classificada como semi-hipógea e as plântulas são do tipo fanerocotiledonar (Figura 2). Tais informações estão de acordo com Moscheta (1995), porém, de acordo com Kuniyoshi (1983), conforme a profundidade da semeadura, o tipo epígeo, também descrito por Leonhardt et al. (2008), pode ser mascarado.

No processo de germinação, inicialmente há hidratação da semente, a qual intumesce, aumentando seu volume. Posteriormente, a partir do $4^{\circ}$ dia, emite a radícula, próxima ao hilo (Figura 2 - A). A raiz primária cilíndrica, esbranquiçada, rapidamente desenvolve-se, engrossando e sofrendo afinamento com dilatação na base (Figura 2 - B). À medida que a raiz se alonga, adquire a coloração amarela e, após 8 a 10 dias, aparecem pelos absorventes, esparsos (Figura 2 - C), de cor pérola. Uma leve dilatação da extremidade apical da radícula marca o início da coifa, que é glabra, de coloração amarelocastanha, cilíndrica, alongada, terminando numa ponta aguda (Figura $2-\mathrm{C}$ ).

O hipocótilo é curto, cilíndrico e esbranquiçado, podendo ser identificado devido ao seu maior diâmetro e ausência de pelos (Figura 2 - D). Considerado de consistência herbácea, possui coloração verde-clara, elevando os cotilédones envolvidos pelo tegumento (Figura 2 - C e D) pouco acima do solo.

Os cotilédones persistentes (Figuras 2 - D a F) iniciam a abertura horizontal após o $15^{\circ} \mathrm{dia}$, sendo maciços, carnosos, opostos, oblongos, com ápice arredondado, base levemente truncada e borda inteira (Figura 2 - E a F), com comprimento de I,5 a $2 \mathrm{~cm}$ e largura de I a I,3 cm. Sua coloração é verde-clara, tornando-se mais escura com o passar dos dias. Entre - $13^{\circ}$ e $15^{\circ}$ dia após a germinação, visualiza-se entre os cotilédones o eófilo de coloração verde-clara (Figura 2 - A) e, ao $30^{\circ}$ dia, a plântula está formada, com raiz pivotante de coloração verde-clara de 7 a $9 \mathrm{~cm}$ de comprimento e raízes secundárias finas (Figura $2-\mathrm{G}$ ). O hipocótilo não se alonga e os cotilédones sésseis, de coloração verde-escura (Figura 2 - G), permanecem ao nível do solo.

O epicótilo cilíndrico possui coloração verdeclara brilhante, medindo em torno de 4 a $5 \mathrm{~cm}$ de comprimento (Figura 2-G). O eófilo é oposto, composto, trifoliolado, com folíolo terminal maior que os laterais (Figura 2 - F). Apenas a primeira e a segunda ordem de eófilos são opostas, todas as demais são alternas.

O desenvolvimento das plântulas entre a emergência e a fase em que possuíam de dois a três pares de eófilos (Figura 2 - F e G) teve duração de um mês, o mesmo relatado por Leonhardt et al. (2008), no entanto, o autor não descreve minuciosamente todas as fases, o que poderá auxiliar a identificação de plântulas a campo.

Após quatro meses da germinação, a muda, já formada, possui altura média de $18 \mathrm{~cm}$ e diâmetro do colo em torno de $3 \mathrm{~mm}$ (Figura $2-\mathrm{H}$ ). O sistema radicular é pivotante, raiz axial lenhosa, com superfície rugosa e ramificações secundárias e terciárias abundantes. 
O colo é cilíndrico e o caule possui entrenós

(Figura $2-\mathrm{H}$ ) de consistência sub-herbácea, com superfície de coloração verde. As folhas adultas (metáfilos) são compostas, pecioladas, alternas, imparipinadas, base foliar arredondada ou obtusa, ápice acuminado, margem inteira, forma oval a ovallanceolada, elípticas a ovado-oblongas. Os folíolos são peciolados, limbo oblongo, base arredondada, aguda, obtusa, ápice obtuso ou arredondado, bordos inteiros e nervação broquidódroma (Figura $2-\mathrm{H}$ ).

Estudos morfológicos de plântulas em sua primeira fase de desenvolvimento, antes da produção das folhas definitivas, são de grande importância, pois permitem a descoberta de estruturas transitórias, primitivas ou derivadas, as quais desaparecem com o desenvolvimento da planta, mas que podem ter relevância para se estabelecer conexões filogenéticas com os grupos em que os órgãos adultos apresentem tais características (RICARDI et al., 1977).

Quanto à fase de muda, não foram encontradas descrições associadas a ilustrações morfológicas, sendo esta informação útil para trabalhos relacionados à produção de mudas e identificação a campo da referida espécie.
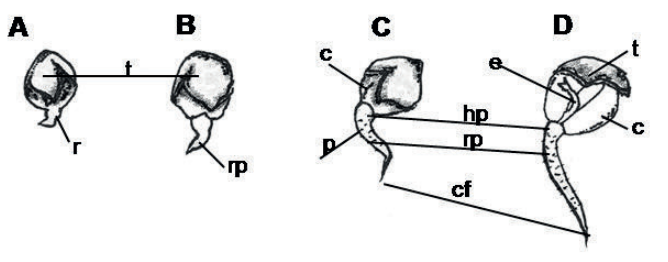

H

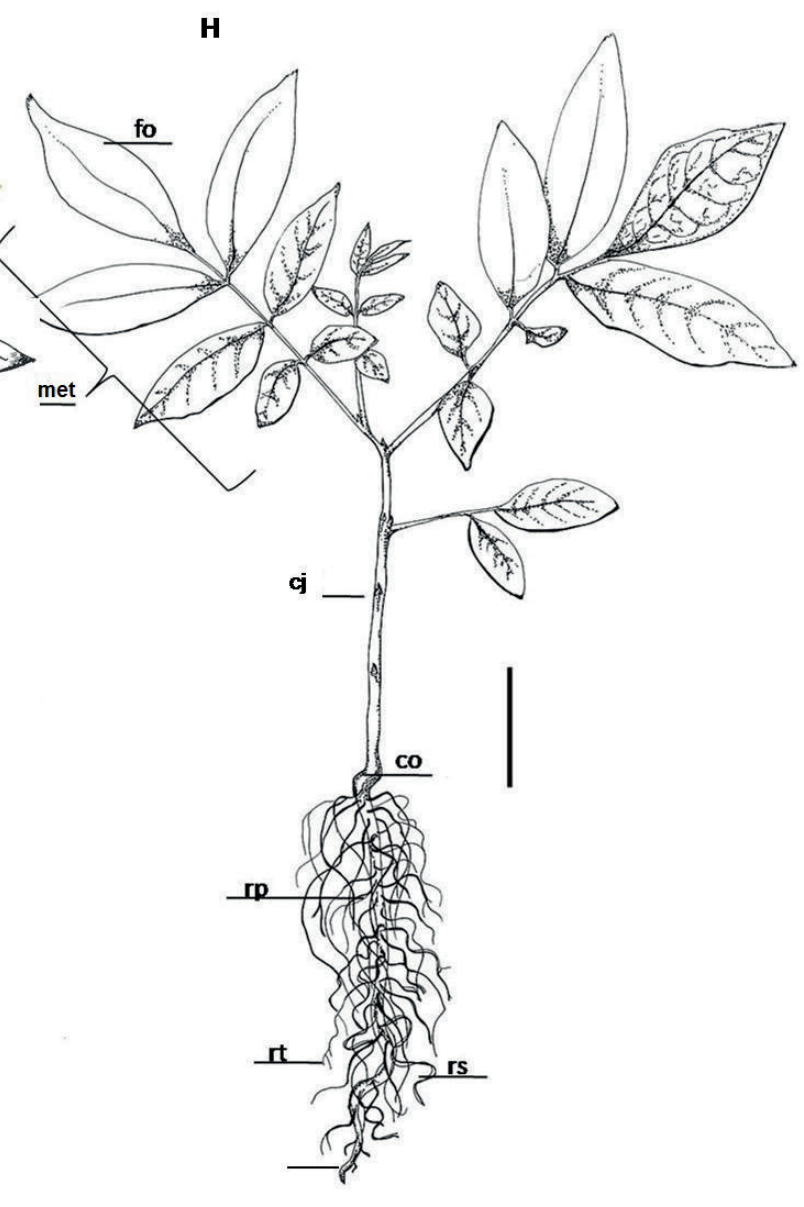

Figura 2 Desenvolvimento inicial de Cabralea canjerana. A a C - Emissão da radícula; D e E - Alongamento da radícula, aparecimento da primeira ordem de eófilos; F e G - Plântula; H - Muda (eof - eófilo; e - epicótilo; c - cotilédone; cf - coifa; cj - caule jovem; co - coleto; fo - folíolo; $h p$ - hipocótilo; met - metáfilo; $\mathrm{p}$ - pelos absorventes; $\mathrm{r}$ - radícula; $\mathrm{rp}$ - raiz primária; rs - raiz secundária; $r \mathrm{rt}$ - raiz terciária; $\mathrm{t}$ - tegumento). Barra: $I, 6 \mathrm{~cm}$ para A a $F, 2 \mathrm{~cm}$ para G e $3 \mathrm{~cm}$ para $\mathrm{H}$.

Figure 2 Initial development of Cabralea canjerana. A to C - Issuance of radicle, D and E - Elongation of radicle, and foliage leaf emergence of the first eophyll F and G - Seedling; H - Changes (eof - eophyll; and - epicotyls; c - cotyledon; cf - hood; cj - young stem; co - collect; fo - folíolo; hp - hypocotyl; met - metaphyll; $\mathrm{p}$ - by absorbing; $\mathrm{r}$ - radicle; rp - primary root; rs - secondary root; $r t$ - tertiary root; $t$ - tegument). Bar: $1.6 \mathrm{~cm}$ for $A$ through $F, G$ to $2 \mathrm{~cm}$ and $3 \mathrm{~cm}$ for $\mathrm{H}$. 


\section{REFERÊNCIAS}

ARAÚJO, E. C.; ARAÚJO, E. C.; MENDONÇA, A. V. R.; BARROSO, D. G.; LAMÔNICA, K. R.; SILVA, R. F. Caracterização morfológica de frutos, sementes e plântulas de Sesbania virgata (Cav.) Pers. Revista Brasileira de Sementes, Pelotas, v. 26, n. I, p. 104-109, 2004.

BACKES, P.; IRGANG, B. Árvores do Sul: guia de identificação e interesse ecológico. Porto Alegre: Instituto Souza Cruz, 2002. 326p.

BAO, F; LIMA, L. B. de.; LUZ, P. B. da. Caracterização morfológica do ramo, sementes e plântulas de Matayba guianensis Aubl. e produção de mudas de diferentes recipientes e substratos. Revista Árvore, Viçosa, v. 38, n. I, p. 63-7I, 2014

BARROSO, G. M.; MORIM, M. P.; PEIXOTO, A. L.; ICHASO, C. L. F. Frutos e Sementes: morfologia aplicada à sistemática de dicotiledôneas. Viçosa: Universidade Federal de Viçosa, 1999. 443p.

BELTRATI, C. M. Morfologia e anatomia de sementes. Rio Claro: Departamento de Botânica da UNESP, 1994. 108p. Apostila do curso de Pós-Graduação em Biologia Vegetal.

BOTELHO, S. A. et al. Aspectos morfológicos dos frutos, sementes, plântulas e mudas de Jatobá-do-cerrado (Hymenaea stigonocarpa Mart. ex Hayne) - Fabaceae. Revista Brasileira de Sementes, Pelotas, v. 22, n. I, p. |44-I52, 2000.

CARVALHO, P. E. R. Espécies arbóreas brasileiras. Colombo: EMBRAPA/CNPR, Brasília: EMBRAPA-SPI, v. I, 2003. 1039p.il.

CORNER, E. J. H. The seeds of dicotyledons. 2v. Cambridge, University Press, v.2, 1976, 558p.

CUNHA, M. C. L.; FERREIRA, R. A. Aspectos morfológicos da semente e do desenvolvimento da planta jovem de Amburana cearensis (Arr. Cam.) A.C. Smith - Cumaru - Leguminosae Papilionoideae. Revista Brasileira de Sementes, Pelotas, v. 25, n. 2, p. 89-96, 2003.

FELIPPI, M. ; LONGHI, S. J. ; ARAUJO, M.M. ; CARON, B. O. Fenologia e morfologia de Diatenopteryx sorbifolia Radlk.. Ciência Florestal, Santa Maria, v. 23, p. 345-353, 2013.

FELIPPI, M. ; MAFFRA, C. R. B. ; CANTARELLI, E. B.; ARAUJO, M.M.; LONGHI, S. J. . Fenologia, morfologia e análise de sementes de Cordia trichotoma (Vell.) Arráb. ex Steud. Ciência Florestal, Santa Maria, v. 22, p. 63I-64I, 2012.
GONÇALVES, E. G.; LORENZI, H. Morfologia vegetal: organografia e dicionário ilustrado de morfologia das plantas vasculares. Nova Odessa: Instituto Plantarum, 20II. $2^{\circ}$ ed. 5 I 2p.il.

GONÇALVES, J. L. M.; BENEDETTI, V. Nutrição e fertilização florestal. Piracicaba: IPEF, 200 I. 427 p.

INOUE, M. T. Indução à deiscência de frutos de Cabralea sp. Floresta, Curitiba, v. 9, n. I, p. I4-18, 1978.

KUNIYOSHI, Y. S. Morfologia da semente e da germinação de 25 espécies arbóreas de uma floresta com araucária. 1983. 233p. Dissertação (Mestrado em Ciências Florestais) - Universidade Federal do Paraná, Curitiba, PR.

LEONHARDT, C.; OLINDA, L.; BUENO, A. C.; CALIL, A. B.; ROSA, R.. Morfologia e desenvolvimento de plântulas de 29 espécies arbóreas nativas da área da Bacia Hidrográfica do Guaíba, Rio Grande do Sul, Brasil. Iheringia, Séria Botânica, Porto Alegre, v. 63, n. I, p. 5-I4, jan/jun. 2008.

MOURÃO K. S. M.; DIAS-PINTO, D.; SOUZA, L. A.; MOSCHETA, I. S. Morfo-anatomia da plântula e do tirodendro de Trichilia catiguá A. Juss., T. elegans A. Juss. e T. pallida Sw. (Meliaceae). Acta Scientiarum, Maringá, v. 24, n. 2, p. 60I-610, 2002.

MOSCHETA, I. S.; SOUZA, L. A.; MOURÃO, K. S. M.; ROSA. S. M. Morfo-anatomia e aspectos da biologia floral de Cabralea canjerana (Vell.) Mart. (MELIACEAE). Acta Científica Venezolana,Caracas, v. 53, p. 239-244, 2002.

MOSCHETA, I. S. Morfologia e desenvolvimento dos frutos, sementes e plântulas de Cabralea canjerana (Vell.) Mart., Guarea kunthiana A. Juss. e Trichilia catigua A. Juss. (Meliaceae - Melioideae). 1995. I60f. Tese. (Doutorado em Ciências Biológicas) - Universidade Estadual Paulista, Rio Claro, SP.

OLIVEIRA, A. K. M. de; SCHLEDER, E. D.; FAVERO, S. Caracterização morfológica, viabilidade e vigor de sementes de Tabebuia aurea (Silva Manso) Benth. \& Hook. f. ex. S. Moore. Revista Árvore, Viçosa, v. 30, n. I, jan./fev. 2006.

PAOLI, A. A. S.; SARTI, J. Morfoanatomia e desenvolvimento de frutos e sementes de Dodonea viscosa (L.) Jacquin. Revista Brasileira de Sementes, Pelotas, v.30, n. I, 2008.

PAOLI, A. A. S.; BIANCONI, A. Caracterização morfológica de frutos, sementes e plântulas de Pseudima frutescens (Aubl.) Radlk. (Sapindaceae). Revista Brasileira de Sementes, Pelotas, v. 30, n. 2, p. I46-I55, 2008. 
PENNINGTON, T.D.AMonograph of theneotropicalMeliaceae. In: PENNINGTON, T. D.; STYLES, B. T.; TAYLOR, D. A. H. Flora neotropica Monograph 28: Meliaceae. The New: York Botanical Garden, 1981. p. I-449.

PENNINGTON, T. D.; B. D. STYLES. A generic monograph of Meliaceae. Blumea, Leichen, v. 22, p. 419-540, 1975.

PIÑA-RODRIGUES, F. C. M.; FREIRE, J. M.; SILVA, L. D. Parâmetros genéticos para colheita de sementes de espécies florestais (p. 5 I a 102). In: PIÑA-RODRIGUES, F. C. M; FREIRE, J. M.; LELES, P. S. dos S.; BREIER, T. B. (Eds.) Parâmetros técnicos para produção de sementes florestais. Seropédica: Rioesba- Rede Mata Atlântica de Sementes Florestais. Seropédica, 2007, 188p.

PIÑA-RODRIGUES, F. C. M.; PIRATELLI, A. J. Aspectos ecológicos da produção de sementes. In: AGUIAR, I. B. de; PIÑA-RODRIGUES, F. C. M.; FIGLIOLIA, M. B. Sementes florestais tropicais. Brasília: ABRATES, 1993. p. 47-8I.

PIZO, M. A. Seed dispersal and predation in two population of Cabralea canjerana (Meliaceae) in the Atlantic Forest of sowtheastern Brazil. Journal of Tropical Ecology, Cambridge, v. I3, p. 559-578, 1997.

PIZO, M. A.; OLIVEIRA, P. S. Interaction between ants and seeds of a nonmyrmecochorous neotropical tree Cabralea canjerana (Meliaceae), in the Atlantic Forest of Southeast Brazil. American Journal of Botany, Columbus, v. 85, p. 669-674, 1998.
REITZ, R.; KLEIN, R. M.; REIS, A. Projeto: Madeira do Rio Grande do Sul. 1988. 525p.

RICARDI, M.; TORRES, F., HERNÁNDEZ, C., QUINTERO, R. Morfologia de plântulas de arboles venezolanos. I. Revista Florestal Venezolana, Caracas, v. 27, p. 15-56, 1977.

RIO GRANDE DO SUL. Governo do Estado. Secretaria Estadual do Meio Ambiente. Relatório Final do Inventário Florestal Contínuo do Rio Grande do Sul. Porto Alegre: SEMA/UFSM, 200I. 706p. v. I, 2.

SANTANA, D. G. de.; RANAL, M. A. Análise da Germinação: um enfoque estatístico. Brasília: Editora Universidade de Brasília, 2004. 248p.

SANTOS, F. S. dos.; PAULA, R. C. de.; SABONARO, D. Z.; VALADARES, J. Biometria e qualidade fisiológica de sementes de diferentes matrizes de Tabebuia chrysotricha (Mart. Ex A. DC.) Standl. Scientia Forestalis, Maringá, v. 37, n. 82, p. 163-173, jun. 2009.

SOUZA, L. A. de. Morfologia e anatomia vegetal: célula, tecidos, órgãos e plântula. Ponta Grossa: UEPG, 2003. 259p.il.

STYLES, B. T. The flower biology of the Meliaceae and its bearing on tree breeding. Silvae Genetica, Frankfurt, v. 2I, n. 5, p. 175-182, 1972

VAN DER PIJL, L. Principles of dispersal in higher plants. 3 ed. Berlin: Springer-Verlag, 1982. 214p. 